\title{
2 \\ Enterprise Simulation Laboratory for simulation games in virtual reality
}

\author{
R. Smeds \\ Helsinki University of Technology, Department of Industrial \\ Management, P.O. Box 9500, \\ FIN-02015 HUT, Finland \\ riitta.smeds@hut.fi
}

\begin{abstract}
The paper presents the Enterprise Simulation Laboratory concept, which is currently being developed at Helsinki University of Technology. At first, the need for visual, interactive enterprise simulation models is put forward. Thereafter, a classification of enterprise simulation models is presented, and the state of the art in enterprise simulation games is analyzed. To fill the gaps in both manual and computer supported enterprise simulations, the idea of a "virtual enterprise space" for simulation is presented. It enables the interactive, visual simulation and experimentation of enterprise systems in a group mode. The Enterprise Simulation Laboratory creates unique research possibilities to apply and study enterprise simulation techniques and organizational learning in a laboratory setting.
\end{abstract}

$$
\begin{aligned}
& \text { Keywords } \\
& \text { enterprise simulation, virtual reality, games, experimentation, } \\
& \text { organizational learning }
\end{aligned}
$$

\section{THE NEED FOR ENTERPRISE EXPERIMENTS THROUGH SIMULATION}

The way an enterprise is "seen" and understood is fundamental for its management as well as for research. However, enterprises are not stable structures, but change as a response to the rapid development of their competitive environments. This poses the challenge for managers and personnel, as well as researchers and students, to continuously learn and update their mental constructs of enterprises.

Experimental Learning in Production Management

R. Smeds \& J. Riis (Eds.)

CC 1998 IFIP. Published by Chapman \& Hall 
Traditionally, industrial companies were perceived as mechanistic systems of functional departments, controlled and managed through the hierarchy of authority. This Tayloristic organization, however, leads today often to sub optimal business performance. This was demonstrated in the 1980's by the superiority of the new business process oriented "lean production" perception of enterprises and enterprise networks, when compared to the old Tayloristic organizations.

Lean management was innovated through painstaking incremental experiments in Japanese companies, starting already in the 1930s. Costly trials and errors helped managers in car industry to understand the enterprises' operational functioning as organic processes rather than as mechanistic functions, and to develop innovative process-oriented management principles (e.g. Schonberger 1982). The lean enterprise was "benchmarked" and adopted by the follower companies, to become a new management paradigm. (Smeds 1994)

At present, new images of industrial enterprises are gaining ground. To answer to increased competition, enterprises have now to be agile: effective, flexible and innovative at the same time. They have to learn and innovate continuously, and evolve in close interaction with their turbulent environment (e.g. Senge 1990, Wheelwright and Clark 1992, Nonaka and Takeuchi 1995, Smeds 1996). The new management implications of this image are however again hard to understand, by managers as well as academia. How does an agile, continuously learning enterprise look like? How does it work? How should it be organized and managed?

Enterprise experiments to create more competitive processes are constantly conducted in companies, and researchers are analyzing and explaining, why they succeed or fail. But trial and error is slow and ineffective, and errors in real life can be fatal. For product innovations, scale models and even virtual prototypes are used for testing out different product concepts before expensive realization. Analogically, for "enterprise innovations", simulation models are needed that allow "enterprise prototyping", the experimentation of an enterprise's organization, its operational processes, strategies and the resulting economic performance before final design and implementation (Smeds 1996, 1997, Riis et al. 1996). To complement and support the "real life learning" in companies, simulations on enterprise models are needed.

\section{MODELING ENTERPRISE SYSTEMS FOR SIMULATION}

\subsection{Technical and social systems}

Enterprise simulation models can be classified according to the nature of the system to be simulated, and the tools used the simulation (Figure 1). For example material flows and layouts of complex production systems, as well as economic systems, are often modeled as technical subsystems of the enterprises. They can be simulated with computer supported mathematical models. Production scheduling simulation packages for companies, as well as software games for education are examples of technical enterprise simulation models. Simulations on the technical models are run by experts, and the outputs can thereafter be used as input in the human decision processes or for training. 
But enterprises do not only consist of technical systems, rather they are complex socio-technical systems, and the models of enterprise processes should also incorporate the social dimension, the interaction of human beings. This can be achieved "manually" in brainstorming and games, but also in a computer supported way, applying virtual reality to support the social simulation (Figure 1). In this hybrid simulation, the people are engaged as actors in the virtual reality model, and can as a group see, experience, experiment and understand the virtual organization and its dynamic functioning.

\begin{tabular}{|c|c|c|}
\hline Manual & $\begin{array}{l}\text { Conretization } \\
\text { Conceptualization } \\
\text { Analytical models } \\
\text { Scale models }\end{array}$ & $\begin{array}{l}\text { Brainstorming } \\
\text { Role games } \\
\text { Board games } \\
\text { Social simulation games }\end{array}$ \\
\hline \multirow[t]{2}{*}{$\begin{array}{l}\text { Computer } \\
\text { supported }\end{array}$} & $\begin{array}{l}\text { Graphical models } \\
\text { Mathematical models } \\
\text { Dynamic models }\end{array}$ & $\begin{array}{l}\text { Hybrid: } \\
\text { Pedagogical animations, } \\
\text { Virtual reality } \\
\text { \& Social simulation }\end{array}$ \\
\hline & $\begin{array}{l}\text { Technical } \\
\text { systems }\end{array}$ & $\begin{array}{l}\text { Social } \\
\text { systems }\end{array}$ \\
\hline
\end{tabular}

Figure 1. A classification of models to simulate enterprise systems

\subsection{Generic and enterprise specific models}

The third dimension to the classification of enterprise simulation models comes from the fact, that the technical as well as social simulation models can be either generic or enterprise specific.

Generic simulation models simulate the behavior of fictive enterprise systems. They can be used for educational purposes, to create awareness and understanding about the general dynamics of enterprises, about new management principles and concepts. Examples like computer supported business games, manual board games and role plays with pedagogical manuscripts are of high value for the education of students, and they can also be used for education of enterprise personnel.

An enterprise specific model is tailored to support the experimentation, development and testing of a specific system of a certain company. Examples are technical layout and material flow simulations, or social simulation games for business process development. 


\section{SIMULATION GAMES FOR SOCIO-TECHNICAL ENTERPRISE SYSTEMS}

A simulation game combines the features of simulation (incorporation of the critical features of the reality into the model) with those of a game (players, rules, competition, cooperation) (Saunders, 1988). The game component adds the social dimension into the simulation model.

An enterprise simulation game is based on a simplified and accelerated model of a selected enterprise process. This model is often physically constructed e.g. on a game board or in a simulation room. The game model and rules should be in relevant aspects as isomorphic with the real process as possible, because they direct and restrict the understanding created by the simulation.

The most important elements in the simulation are the players of the game. The dynamic operation of the process is simulated through their action and communication. Thus also the composition of the game group is important. The simulation games are often facilitated by one or several facilitators.

\subsection{Generic enterprise simulation games}

Generic enterprise games are often based on a manual model. For example a production system game can be built of a game board, physical material, written rules and documents. The game is played according to the rules by human players occupying fictive roles (e.g. Schierholt and Brütsch, in this volume, Alstrup and Busk Kofoed, in this volume). Some of these generic games are available as commercialized products, e.g. ADVANTIG (Gertsen 1995), and the Lego Truck Game (Johansen and Mikkelsen 1995). A facilitators typically assists in the game runs and discusses the results in the debriefings together with the players.

To a growing extent, the economic calculations and the technical subsystem simulations during the games are conducted on computer-based mathematical models (e.g. Zulch et al., in this volume, Mulder et al., in this volume).

Generic business games are frequently used in university education. They simulate the economic performance and competition of companies based on mathematical computer models. Through the inclusion of team work and seminars into decision making and reporting during the game, the social dimension can to some extent be incorporated into the basically very "technical" business simulation. (e.g. Smeds et al. 1996)

\subsection{Enterprise specific simulation games}

The enterprise specific simulation games are based on tailored models of company processes, and on company data. Typically, a rough model of the process is first created as an analytic description (flow chart) of the activities and the information and material flows. Then it is manually constructed, e.g. by furnishing a seminar room as a "scale model" of the process, with adequate paraphernalia and process materials. In the game itself, the players fill in the relevant details and much of the coordination and cooperation rules of the enterprise process. 
The composition of the game team is important for the validity of the simulation model. The team should mirror the organization of the process as closely as possible; ideally all employees and managers engaged in the real process should participate also in the simulation. The players act in their own work roles. They act and "talk through" the activities and information and material flows of the process, following the route of a concrete case example, e.g. a specific customer order, and using supporting case material. Observers, e.g. support staff from the company's development functions, representatives from other departments or organizations can participate in the game and in the discussions, depending on the focus of the game. If top managers participate in the game, also the strategic and policy aspects of process operations can be included in the simulation (e.g. Smeds 1996).

Through the human interaction and discussion in the game, tacit knowledge of the process is externalized and shared, and a common understanding is created. Development ideas, problems and open questions concerning the process are awakened and written down for further use in smaller process development teams. The teams refine the ideas into a new process design to be tested in a prototyping manner in the subsequent simulation games (e.g. Smeds and Haho 1995a, b, 1996, Haho and Smeds 1997a, b, Forssén-Nyberg and Hakamäki, 1997, Ruohomäki 1995, Haho, in this volume, Forssén-Nyberg and Kutilainen, in this volume, Pankakoski, in this volume).

Enterprise specific simulation games are efficient methods for process innovation (Smeds 1994, 1996). Therefore the choice of the target process and the objectives for the process "prototyping" should be based on strategic analysis. Sometimes, the first simulation game becomes itself an important method to clarify and define the strategic objectives for the process re-engineering project. (Smeds 1996, 1997)

Although the models of enterprise specific games are tailored, the methods and procedures for building the models and for running the games can to some extent be standardized (e.g. Piispanen et al. 1996, Haho and Smeds 1996, 1997a, b). There exist also enterprise specific games, where the technical subsystem simulations are run on a computer model. This enables an accelerated simulation e.g. for capacity planning in the production process (e.g. Savukoski et al. 1995).

\subsection{The need for new tools to support simulation games}

The social simulation that is necessary in both the generic and specific enterprise games is achieved through human interaction, discussion and experimentation during the game. But the ways in which this human interaction is supported by manual or computerized tools varies. Both manual and computerized tools have their limitations.

In the manual games, the alternatives that can be jointly experimented are restricted by the limitations of the physical place and material, and also time, since the game runs have to be performed manually.

Using computerized tools in some parts of the simulation can cause limitations, since the dynamics of the game is restricted by the mathematical model and hidden into computer program, and thus cannot be "seen" and acted upon by the players. 
Virtual reality gives new technological possibilities to overcome these limitations. Through the use of the latest achievements in multimedia, computer graphics and visual programming, a visual interactive model can be created for the group simulations and experimentations of both generic and specific enterprise systems. This is the development idea of the new Enterprise Simulation Laboratory at Helsinki University of Technology.

\section{THE ENTERPRISE SIMULATION LABORATORY CONCEPT}

The Enterprise Simulation Laboratory is being developed in a three year project 1997-2000 at Helsinki University of Technology, TAI Research Centre, as a collaborative effort of three laboratories: Industrial Economics, Industrial Psychology, and Telecommunication Software and Multimedia (TLM). The Laboratory aims to answer to the challenges of social simulation in both generic and enterprise specific models in a unique, multidisciplinary way: it supports the interactive human experimentation through the creative combination of existing enterprise simulation games, dynamic mathematical models, and virtual reality.

\subsection{The virtual "enterprise space" for enterprise simulations}

In the Enterprise Simulation Laboratory, the virtual reality for simulations will be created through the virtual wall concept ${ }^{1}$ (Takala 1997):

On one wall of the laboratory, a huge three-dimensional picture of the simulated system is projected from a computer display. This picture can be flexibly modified applying computer graphics and e.g. video picture. The virtual wall gives almost unlimited possibilities to visually model the enterprise "space", from the simple furnishing of the simulated room (e.g. applying animation) to the visual presentation of data, and even to the telepresence of the players in the virtual space (immersive virtual reality). Every player can simultaneously see and experience the wall, which enables a shared, social simulation experience.

During the simulation games, the virtual wall can support visual experimenting of enterprise processes in at least five different ways:

1) Conceptual simulation data can be projected to the wall, for every player to see: e.g. the layouts and process charts, performance measures, economic analyses of the processes; also outputs from mathematical simulations of the technical subsystems, if they are applied during the simulation game.

2) The physical simulation environment can be visualized in a two- or threedimensional form: e.g. the future layout of the new company, the view of the workshop with its machines, the material flows and even the movements of virtual actors in the workshop. - The facilitator can change these images flexibly and quickly on the screen, even during the simulation.

\footnotetext{
${ }^{1}$ The best known virtual space application, called CAVE, has been developed at University of Illinois at Chicago.
} 
3) The players can interact directly with the virtual wall model, e.g. change the layout of the factory and the location of the machines in the workshop.

4) The players can immerse themselves into the virtual reality, e.g. into the planned future factory, and experience the space and the functioning of the factory from "within".

5) Even players at different geographical locations can participate in the same simulation, if the virtual wall picture is transmitted via interactive broadband telecommunication networks simultaneously to several locations. The players can interact applying CSCW technologies and interactive video, and even meet each other as virtual actors in the "enterprise space". The Enterprise Simulation Laboratory is thus not necessarily tied to one location, but can exist in a telematic network.

The two first points on the list above can be achieved with existing multimedia software, hardware, and simulation game methods, but the latter points require multidisciplinary research and development effort to create software and equipment for an appropriate user interface for the virtual "enterprise space".

\subsection{Developing the Enterprise Simulation Laboratory}

The Enterprise Simulation Laboratory's virtual "enterprise space" is a challenging multidisciplinary research agenda for the next three years. It is developed in a "concurrent engineering mode" with three cutting edge Finnish industrial companies representing machine industry, telecommunications and medical industry (Figure 2).

The needs of these pilot companies set high requirements for the Laboratory:

1) Pilot company A wants to develop a visual, generic simulation game to train the whole personnel in understanding the operations and strategies of a typical industrial company, and the connections between operational processes and economics.

2) Pilot company $B$ is growing rapidly, and is moving to a new factory. It needs tailor-made technical and social simulation support to re-engineer its layout, production lines, material flows, and later its global logistic chains. The company is also in the process of implementing a new operations control system, and has to train its employees to the new processes.

3) Pilot company $\mathrm{C}$ is re-organizing its highly complex, knowledge intensive $R \& D$ process of medical drugs, and needs interactive social simulation games to be able to dramatically decrease the lead time of new product development.

The Enterprise Simulation Laboratory project proceeds in a prototyping manner with the three parallel pilots. For each pilot company, simulation model prototypes are developed and tested with company test groups. The evaluations of the prototypes' usability, learning effects, effects on innovations, as well as the technical requirements of software and graphics are important feedback for the development of the subsequent versions of the models and of the whole Enterprise Simulation Laboratory. (Figure 2) 
Special emphasis has to be put from the start of the development project on the validity of the models and the learning effects of the simulations. The experiences that are created in the virtual enterprise space have to equal in relevant aspects the real enterprise processes, otherwise the players will learn the wrong lesson.

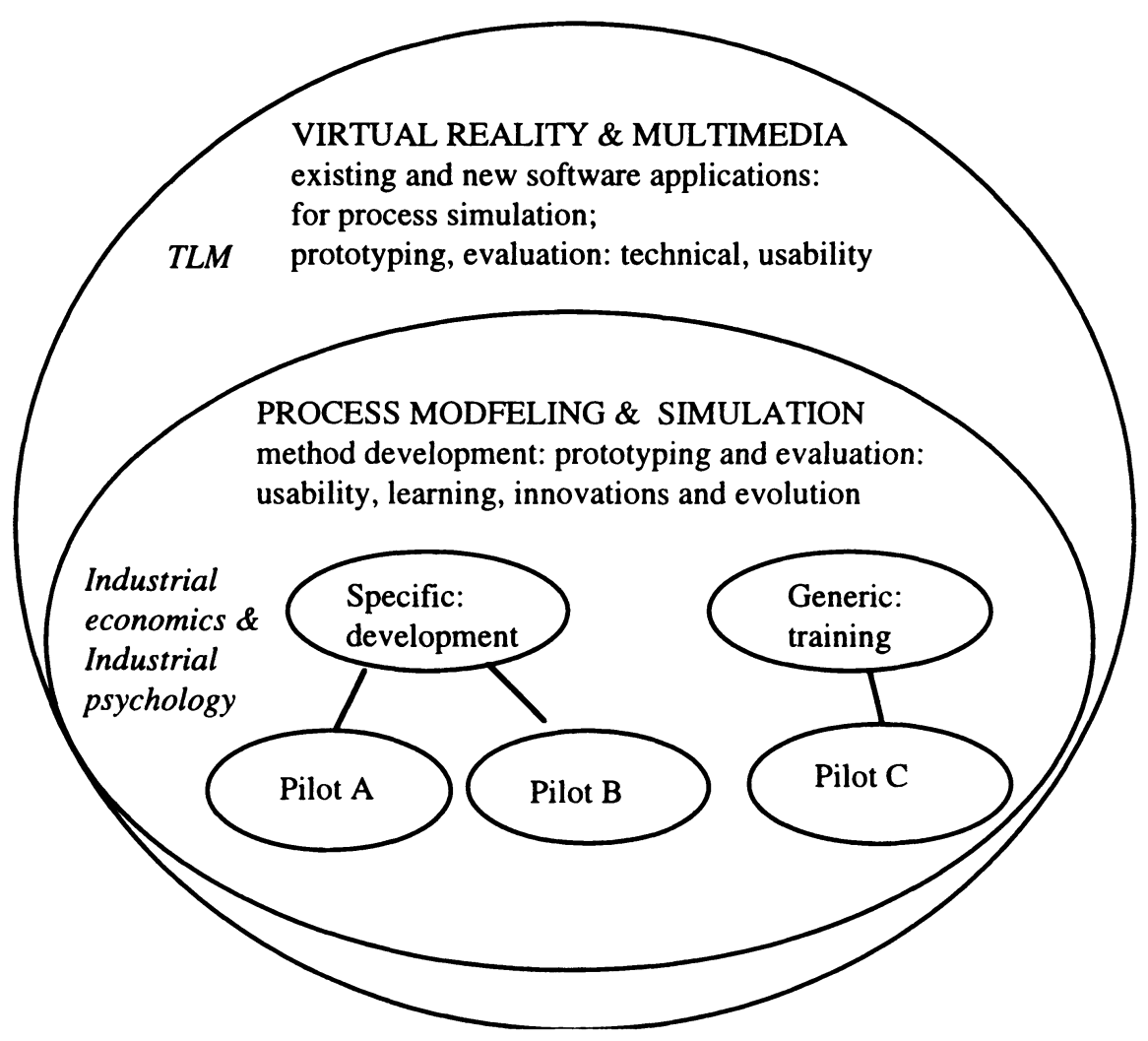

Figure 2. The development concept of the Enterprise Simulation Laboratory

\subsection{The Enterprise Simulation Laboratory in future use}

The Simulation Laboratory at Helsinki University of Technology is planned to continue its functioning after the three year development project, to serve three main user groups: the students, the industry practitioners and the researchers. 
The Laboratory's technical construction, the virtual wall, can be applied to enable visualization and experimentation in the teaching of Industrial Management courses. E.g. computer simulation displays like the business game outputs after each game round can be projected on the virtual wall for the joint analysis and discussions by student groups. Cooperative work on the same model is possible on the virtual wall, and the combination of the virtual wall with telematics creates new possibilities also for students to engage in distant collaboration and learning. (cf Augustin, in this volume)

Practitioners from industry can firstly be invited for educational generic simulations to the Laboratory. But secondly, and more importantly, they can use the Laboratory as an "enterprise clinic" for their enterprise specific problem solving and process development tasks. Development groups can attend simulation games, which are tailored to the enterprises' needs and played in the virtual enterprise space of the Laboratory. This possibility is especially valuable in the simulation of an enterprise's future processes, where manual models would be too limited, rudimentary, and slow, and computerized mathematical models would inhibit the necessary social interaction for experimentation, synthesis and understanding. - The telepresence of players in the game makes it possible to simulate global processes of enterprises through the virtual meeting of players in the same simulation.

Multidisciplinary research teams will have excellent possibilities to study virtual reality and multimedia simulations of enterprise processes, as well as their user interfaces and learning effects, already in the prototyping phases of the project. Later, as an enterprise clinic, the Enterprise Simulation Laboratory will become a unique facility for research on new enterprise modeling and simulation techniques, and especially on the complex phenomenon of organizational learning. While using the Laboratory as a clinic for their internal development and problem solving tasks, the enterprises will provide rich empirical data for research on organizational decision making, innovation and experimental learning.

\section{REFERENCES}

Forssén-Nyberg, M. and Hakamäki, J. (1997) Development of the production using participative simulation games, International Journal of Production Economics, (in press)

Gertsen, F. (1995) ADVANTIG - ADVANced Technology Implementation Game, In: Jens Riis and Hans Mikkelsen (eds): Simulation Games and Learning in Production Management. Chapman \& Hall, London, 156-162.

Haho, P. and Smeds, R. (1996) Benefits from using simulation games in business process development. Experiences from a Finnish manufacturing company. In: N. Okino, H. Tamura and S. Fujii (Eds.) Advances in Production Management Systems. Proceedings of the 6th IFIP TC5/WG5.7 International Conference APMS '96, Kyoto, Japan, 4-6 November, 1996, 267-272.

Haho, P. and Smeds, R. (1997) The Softmatch-method: Enterprise Transformation through Simulation Games. In: Peter Saunders and Benita Cox (Eds.): The Simulation and Gaming Yearbook Volume 5. Kogan Page, London, 48-63. 
Haho P., Smeds, R., Laine K., Gustafsson B., Blatti S., and Birbaum, D. (1997) The Softmatch Method. Management of Business Process Development Projects Using Simulation Games. Process Developer's Manual, S.A.M.I. Oy, Helsinki.

Johansen, J. and Mikkelsen, H. (1995) The Lego truck game, In: Jens Riis and Hans Mikkelsen (eds): Simulation Games and Learning in Production Management. Chapman \& Hall, London, 127-133.

Nonaka, I. and Takeuchi H. (1995) The Knowledge Creating Company, Oxford University Press, Oxford.

Piispanen, E., Ruohomäki, V., Pankakoski, M. and Teikari, V. (1996) The Work Flow Game - a new method for developing office work. In: D. Saunders, F. Percival and M. Vartiainen (Eds.): The Simulation and Gaming Yearbook Volume 4. Kogan Page, London, 85-95.

Riis, J., Smeds, R., Johansen, J. and Mikkelsen, H. (1996) Games for organizational learning in production management. In: N. Okino, H. Tamura and S. Fujii (Eds.) Advances in Production Management Systems. Proceedings of the 6th IFIP TC5/WG5.7 International Conference APMS '96, Kyoto, Japan, 4-6 November, 1996, 277-282.

Ruohomäki, V. (1995) A simulation game for the development of administrative work processes, In D. Saunders (Ed.) The Simulation and Gaming Yearbook, Volume 3, Games and Simulations for Business, Kogan Page, London, 264270.

Saunders, D. (1988) 'Preface' in Learning from Experience through Games and Simulations. In: D. Saunders, A. Coote and D. Crookall (Eds.) The proceedings of the 1987 conference of SAGSET, the Society for the Advancement of Games and Simulations in Education and Training; held at Dyffryn House, Cardiff. Sagset, Cardiff, 9-12.

Savukoski, E., Plukka, S., Enestam, V., Savolainen, M. and Piltonen, P. (1995) The Enterprise Game - real process simulation, In: D. Saunders (Ed.) The Simulation and Gaming Yearbook, Volume 3, Games and Simulations for Business, Kogan Page, London, 254-263.

Schonberger, R. J. (1982) Japanese Manufacturing Techniques. The Free Press, New York.

Senge, P. (1990) The Fifth Discipline. The Art and Practice of The Learning Organization. Doubleday, New York.

Smeds, R. (1994): Managing Change towards Lean Enterprises. International Journal of Operations \& Production Management, 14 (3) pp. 66-82.

Smeds, R. (1996) Management of Enterprise Evolution. Evolution Management Principles and Methods for Learning Organizations. Doctoral Dissertation. Acta Polytechnica Scandinavica, Mathematics, Computing and Management in Engineering Series No. 80, The Finnish Academy of Technology, Helsinki.

Smeds, R. (1997) Organizational learning and innovation through tailored simulation games: Two process re-engineering case studies. Knowledge and Process Management. The Journal of Corporate Transformation 4 (1) pp. 2233.

Smeds, R. and Haho, P (1995) Tailored order-to-delivery process game. In: Jens Riis and Hans Mikkelsen (eds): Simulation Games and Learning in Production Management. Chapman \& Hall, London, 145-155. 
Smeds, R. and Haho, P. (1995) Simulation games in business process reengineering, In: D. Saunders (Ed.) The Simulation and Gaming Yearbook, Volume 3, Games and Simulations for Business, Kogan Page, London, 246253.

Smeds, R., Tarkiainen, M. and Virtanen, T. (1996) Educational business simulation on the Internet, in Y. Merkuryev and Rapp, B. (Eds.) Abstracts of the International Conference on Simulation, Gaming, Training and Business Process Re-engineering in Operations, The International Federation of Operational Research Societies Special Conference, September 19-21, Riga, Latvia, p. 17.

Wheelwright, S.C. and Clark, K.B. (1992) Revolutionizing Product Development. Quantum Leaps in Speed, Efficiency, and Quality, The Free Press, New York.

Takala, T. (1996) Building a virtual reality space at Helsinki University of Technology, Internal Memorandum, Laboratory of Telecommunication Software and Multimedia, unpublished (in Finnish)

\section{BIOGRAPHY}

Riitta Smeds is the head of the Enterprise Simulation Laboratory at Helsinki University of Technology. She holds a M.Sc., a Lic. Tech. and a D. Tech in Industrial Management from HUT. She is a member of IFIP Working Group 5.7 on Computer Aided Production Management Systems, the International Foundation for Production Research IFPR, and of the European Group for Organizational Studies EGOS, and belongs to the editorial board of "Knowledge and Process Management, The Journal of Corporate Transformation". Her main research areas are enterprise evolution, management of technology and innovation, organizational learning, and enterprise simulation methods. 